\title{
ESTUDIOS
}

\section{La prensa chicha: un análisis cognitivo}

\author{
Raymundo Casas Navarro \\ Universidad Nacional Mayor de San Marcos \\ raycasasn@gmail.com
}

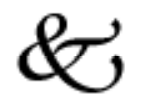

\section{Resumen}

El presente artículo se aboca al estudio del comportamiento de las formas verbales que aparecen en los denominados periódicos "chicha» de la ciudad de Lima (Perú). El análisis de estas formas discursivas involucra dos aspectos complementarios: En primer término, se incide en cómo se estructura el núcleo verbal con respecto a sus adjuntos (opcionales y obligatorios), lo que denominamos análisis funcional. En segundo lugar, se propone un análisis cognitivo para dar cuenta de cómo se configura la riqueza del sentido de tales formas verbales. Como fruto del trabajo de interpretación, se establece que la modalidad discursiva de estos textos permite omitir ciertos adjuntos obligatorios, los cuales se pueden inferir por el contexto y el cotexto. Asimismo, se postula que en la conformación del sentido de estas formas verbales operan diversos efectos retóricos (como la metáfora, la metonimia, la sinécdoque, la antífrasis y la hipérbole) proyectados por mecanismos cognitivos de naturaleza subyacente.

Palabras claves: Análisis funcional, análisis cognitivo, procedimientos retóricos, prensa «chicha».

\begin{abstract}
This paper attempts to study the verb forms that appear in the newspapers named "chicha" in Lima (Perú). To fulfill this scientific task, we will hold two procedures: first, a functional analysis in the sense of glossematics or in Martinet terms; second, a semantic analysis framed in cognitive linguistics. As a result of these procedures, we will bring to light the structure and the value of sentences, and the formation of deep
\end{abstract}


meanings according to the hypothesis of "chicha" imagery. In short, the various verb forms are projections of underlying cognitive mechanisms.

Keywords: Functional analysis, cognitive analysis, rhetorical procedures, "chicha" tabloids.

\section{Introducción}

Tradicionalmente, los medios escritos de comunicación de masas empleaban la lengua estándar para referir sus noticias y expresar sus comentarios. Sin embargo, en muchas partes del mundo surgió un tipo de prensa, llamada sensacionalista, que produjo un ostensible viraje para que su estilo de lengua esté acorde con su particular contenido. La idea era impactar al lector común con noticias escabrosas, redactadas - por lo menos en los espectaculares titulares- con un lenguaje basilectal. Este viraje se ha consolidado como una modalidad linguística propia en un tipo de prensa limeña, la denominada prensa «chicha».

El término "chicha» [una voz aborigen de Panamá que significa 'maíz' (DRAE 2001)] ha adquirido una notable polisemia en el lenguaje peruano. Nos interesa notar aquí dos valores de este lexema que deben ser rigurosamente distinguidos para evitar confusiones. Cuando se habla de "música chicha» $\mathbf{O}$ "cultura chicha», la acepción pertinente alude a una especie de sincretismo (o neutralización) entre la cultura occidental y la cultura andina. En cambio, cuando se habla de "prensa chicha» se alude a un producto informal, de mal gusto y de baja calidad. Estos rasgos sémicos son muy pertinentes en las diferentes valoraciones que se hacen en torno a los mensajes de esa prensa, bastante estigmatizada. Se puede barruntar que el estilo informal o "chicha» es deliberado y, como tal, una tecnología de la información que obedece a una amplia gama de motivaciones (desde las crematísticas más patentes hasta las ideológicas más latentes).

La prensa chicha emplea el basilecto, esto es, la variedad básica, la más alejada del estándar (Bickerton 1975; Lang 2000) como una manera de establecer un contacto natural con el tipo de lector a que 
va dirigida. Si el objetivo es impactar al lector de este tipo de periódico, el uso de formas acrolectales no sería adecuado. Por ello, suele emplear lo que se conoce como jerga, término no exento de cierta polisemia. Por ejemplo, en el estudio de Augusto Alcocer (2001) se usa el término en el sentido de una variante sociolectal restringida al dominio léxico, aunque tradicionalmente se ha definido como un "conjunto de palabras procedentes de fuentes oscuras (deformación de extranjerismos y traslación semántica de voces de uso general con sentido ocasional normalmente), que por broma o ironía se introducen en la conversación familiar de todas las clases sociales» (Lázaro Carreter 1968: 252). El empleo de registros basilectales por parte de la prensa "chicha» es muy funcional por cuanto se trata de captar la atención de la "gente del pueblo» mediante un tipo de lenguaje que es usado cotidianamente y que exhibe eficacia comunicativa. Ello explicaría los grandes tirajes de estos medios periodísticos y que, cada cierto tiempo, surja un nuevo periódico para competir en el mercado. Una razón adicional radicaría en facilitar la comprensión lectora (Cappelini 2004), dado que los destinatarios de este tipo de publicación suelen practicar la lectura ocasional, casi ‘al vuelo’ (una cantidad no menor de personas solamente lee las páginas titulares o centrales dispuestas en los quioscos). El estilo basilectal, propio de los textos chicha, cumple con un propósito fundamental: garantizar el cumplimiento de la intención comunicativa.

El comportamiento verbal de los enunciados de estos periódicos se puede analizar de diversas maneras. Mediante el análisis funcional, la descripción del verbo se efectúa en términos de núcleo y adjuntos, ya que la función se entiende como la relación de dependencia entre dos elementos que, desde la tradición de la glosemática hjelmsleviana, se denominan funtivos (Hjelmslev 1970). Se deduce de lo anterior que para el análisis sintáctico no usamos el término función de acuerdo con los presupuestos del funcionalismo de la Escuela de Praga (esto es, función entendida como intención comunicativa). La función predicativa (i.e., la eminentemente verbal) se cristaliza añadiendo al núcleo verbal una serie de adjuntos (como 
sujeto, objeto directo, objeto indirecto, circunstancial), algunos obligatorios y otros opcionales.

Dado que el análisis sintáctico funcional, en el sentido glosemático, no atañe a la intención comunicativa, se requiere llenar ese vacío con otro tipo de enfoque: el análisis cognitivo. Este concibe las construcciones gramaticales como recursos que permiten configurar el sentido verbal para alcanzar la eficacia comunicativa. Esta manera de configuración semántica traslaticia permite corroborar la idea de que la inferencia es crucial en todo proceso de comunicación linguiística y es la causa eficiente de toda praxis comunicativa exitosa.

El presente trabajo se aboca al estudio del comportamiento de las formas verbales que aparecen en los denominados periódicos «chicha» de la ciudad de Lima (Perú) en el período de 1999 a 2005, en virtud de los siguientes parámetros analíticos:

\section{Análisis funcional}

Como núcleo del predicado, el verbo puede tener varios adjuntos o argumentos diferentes. En algunos casos, estos argumentos son obligatorios (esto es, deben aparecer necesariamente en la estructura sintáctica) y otros son opcionales. Aunque se ha dicho que los adjuntos circunstanciales son de índole opcional en la estructura oracional, cabe notar que en el análisis del discurso son muy necesarios para recuperar el sentido global de la noticia. Obviamente, como el titular sólo presenta la noticia, y no la desarrolla, puede omitir en su estructura superficial a los adjuntos circunstanciales.

El análisis funcional permite establecer que la sintaxis de una oración se organiza mediante la incidencia en torno a un núcleo y la incidencia se entiende como el desarrollo de adjuntos. Respecto de los denominados adjuntos opcionales, se puede decir que éstos no se visibilizan siempre en la estructura porque se pueden recuperar mediante el contexto y el cotexto. Así, por ejemplo, intuiciones preanalíticas constatan una versatilidad en el uso (o no uso) de la preposición como marca de objeto directo humano, lo que quizá 
podría atribuirse a que el orden básico del castellano es sujeto - verbo - objeto y la aplicación de ese orden evita cualquier ambiguiedad.

El presupuesto fundamental de este análisis funcional radica en una vieja consideración de Martinet, según la cual la comprensión "de las estructuras sintácticas más variadas requiere una investigación de todos los posibles medios de indicación de función, i. e., de conexión de los diversos componentes de un enunciado coherente" (Martinet 1978: 303).

\section{Análisis cognitivo}

Procedimientos conocidos como retóricos (metáforas, metonimias e ironías) son, en realidad, procesos cognitivos muy rentables en la construcción del sentido del lenguaje cotidiano. En los textos de la prensa «chicha» operan traslaciones semánticas muy útiles en la configuración del sentido de los mensajes. En este aspecto del análisis, una noción importante es la de imaginería (imagery, en inglés) definida por Langacker (1987: 110) como «our ability to construe a conceived situation in alternate ways -by means of alternate images- for purposes of thought or expression». Un corolario de esta concepción es que una misma situación concebida con imágenes diferentes conlleva a diferentes maneras de construcción gramatical. Así, las imágenes cognitivas de los siguientes enunciados difieren por el cambio (shift) en la preposición: la imagen dinámica de (a) contrasta con la estática de (b).

(a) Carmen está por la avenida Piérola.

(b) Carmen está en la avenida Piérola.

Este tipo de análisis, aplicado a las formas discursivas utilizadas por la prensa chicha, podría echar luces sobre la manera como la cultura configura el lenguaje cotidiano y como el lenguaje cotidiano transforma la propia cultura. El anterior corolario se puede ilustrar con la teoría de los espacios mentales de Fauconnier $(1994,1998)$, según la cual las formas discursivas constituyen claves para interpre- 
tar los procesos cognitivos que tienen lugar detrás de las escenas verbales que visualizamos directamente. Las modalidades discursivas esconden procesos subyacentes de la dinámica de la cognición humana, y el análisis cognitivo busca desentrañar la manera como trabaja la mente al producir o comprender los textos de la vida cotidiana. Si la estructura gramatical se configura como un conjunto de escenas (Tesnière 1959), la perspectiva cognitiva apunta a lo que hay detrás del escenario. En este punto, resulta pertinente considerar las reflexiones de Kosslyn (1994) en la medida en que brindan un marco para entender cómo se generan las imágenes en el cerebro y, luego, cómo se proyectan en los mensajes verbales, auténticos vicarios de las representaciones mentales.

\section{La punta del iceberg: algunos ejemplos de la prensa chicha}

Como una manera de abordar el lenguaje basilectal de la prensa "chicha» limeña, presentaremos un conjunto de enunciados extraídos de los titulares de algunos periódicos representativos (Trome, Ajá, El chino, El popular, Extra). Aunque no es un corpus exhaustivo, creemos que es bastante representativo de la modalidad discursiva de estos medios de masas. Se puede colegir, con facilidad, que cada enunciado podría multiplicarse ad libitum ya que los enunciadores (esto es, los periodistas que laboran en tales rotativos) operan con recursos ilimitados.

(1) Naranjeros pasan por caja. Este titular se refiere a que los jugadores del equipo de fútbol denominado Huaral hicieron efectivo el cobro de sus haberes.

(2) Se le para bobo en pleno chuculún. Este titular se refiere a que un individuo sufrió un paro cardiaco durante un encuentro sexual.

(3) Taxi hace puré a loquito. Este titular informa que un alienado se arrojó a la vía rápida y un auto lo arrolló.

(4) 'Yucrín' pelaba enamorados con cuchillo. El titular describe que un delincuente robaba a parejas de enamorados asaltándolos cuchillo en mano. 
(5) Polo Campos se plancha cacharro. El titular se refiere a que el referido compositor se somete a una cirugía facial rejuvenecedora.

(6) Rubí chanca a forro. El titular nos informa de que la famosa vedette Rubí Berrocal estudia con ahínco.

(7) Dina Páucar cantó con lágrimas. El titular describe que la cantante dio su testimonio en un proceso judicial.

(8) Monos florean al ciego. La noticia se refiere al hecho de que los ecuatorianos alaban al técnico peruano de fútbol Juan Carlos Oblitas.

(9) Fuego achicharra hermanitas. El titular se refiere a que dos niñas mueren por la acción de un incendio.

(10) Mufarech mañana mueve la lengua para soltar descargos. El titular se refiere a que el congresista Mufarech hará su descargo frente a una comisión del Congreso.

(11) «Lulú» arruga y no apoyará interpelación contra Charlie. El titular refiere que la lideresa política Lourdes Flores se arredra frente a la interpelación contra el ex ministro Carlos Ferrero.

(12) Chapan a «Tula» limpiando jatazo. El titular nos informa de la captura de una ladrona, apodada Tula, mientras robaba en una mansión.

(13) Teutón da vuelta "veci» por no aceptar pizza. El titular refiere que un ciudadano alemán asesina a una vecina por despreciar una invitación a comer.

(14) Ingeniero se forró con 600 dólares. El titular refiere que un ingeniero ganó el premio económico que otorga el periódico.

(15) Plomean chibolo chichero. El titular nos informa de que un joven fue herido de bala.

(16) Piratas calatean 50 pasajeros en bus. El titular nos informa de un asalto sufrido por cincuenta pasajeros en un ómnibus interprovincial. 
(17) Gripe tumba a Chichi Valenzuela. El titular se refiere a que la conspicua periodista Cecilia Valenzuela contrajo un fuerte resfrío que la obligó a tomar descanso.

(18) Chapan 'Rey del bujiazo'. El titular refiere que un peligroso delincuente, conocido como 'Rey del bujiazo', fue capturado luego de haber robado a un chofer.

(19) Chakana se limpia de firmas falsas. El titular informa que los más altos dirigentes del Partido Perú Posible negaron tajantemente haber falsificado firmas para lograr su inscripción en 1998.

(20) A Autuori le dijeron de todo en aeropuerto. iVaya "piropos»! Se informa de los agravios proferidos contra el ex director técnico de la selección de fútbol, Paulo Autuori.

(21) Por soplón matan a “drogo" de tres tiros... pero de bala. El titular refiere que un drogadicto fue asesinado por haber hecho una delación.

(22) Choledo: «Nos dan con machete». El titular hace una paráfrasis de una queja del ex presidente Toledo en relación a las duras críticas que recibió.

\section{Análisis funcional}

Como núcleo del predicado, el verbo puede tener hasta cinco adjuntos diferentes: sujeto, objeto directo, objeto indirecto, circunstancial y predicativo (Alarcos 1994). Un postulado del análisis tradicional es señalar que algunos de estos argumentos son obligatorios (esto es, deben aparecer necesariamente en la estructura sintáctica) y otros son meramente opcionales (esto es, su presencia no sería necesaria ni suficiente para establecer la estructura oracional). Aunque se ha dicho que los adjuntos circunstanciales son de índole opcional en la estructura oracional, cabe notar que en el análisis del discurso son muy necesarios para recuperar el sentido global de la noticia. Obviamente, como el titular sólo presenta la noticia, y no la desarrolla, puede omitir en su estructura a los adjuntos circunstanciales. 
El análisis se aplica por igual tanto a verbos simples (como pelar, plomear) como a locuciones verbales (pasar por caja, hacer puré). Las locuciones verbales son construcciones cuyas palabras no admiten ni conmutación estructural ni conmutación léxica. Dado que se conmutan como un todo holofrástico, se podría decir que son construcciones endocéntricas.

El enunciado (4) tiene como núcleo la forma "pelaba» y sus adjuntos son:

Sujeto: Yucrín. Objeto directo: enamorados. Circunstancial: con cuchillo. Notamos que el sujeto es aquí el agente de la acción y se ha omitido la preposición «a» que normalmente acompaña a la FN de objeto directo cuando se trata de una persona. Se observa que tanto el sujeto como el objeto directo son adjuntos obligatorios. El cotexto permite inferir que, en este caso, el circunstancial se refiere a un valor instrumental.

El enunciado (5) tiene como núcleo la forma "se plancha» y sus adjuntos son:

Sujeto: Polo Campos. Objeto directo: cacharro. Notamos que el sujeto aquí es paciente (se infiere que los agentes son unos médicos cirujanos). El objeto directo del verbo es «cacharro», la parte del cuerpo sometida a la cirugía rejuvenecedora.

El enunciado (6) tiene como núcleo la forma «chanca» y sus adjuntos son:

Sujeto: Rubí. Circunstancial: a forro. El sujeto expresa a un agente. Notamos que el verbo tiene un adjunto interno (complemento de objeto directo) que permite establecer la sinonimia con el verbo «estudiar». El circunstancial es un intensificador y el contexto permite establecer la finalidad de la acción representada por la forma verbal.

El enunciado (7) tiene como núcleo la forma «cantó» y sus adjuntos son:

Sujeto: Dina Páucar. Circunstancial: con lágrimas. Aquí, el sujeto cumple un papel de agente. Notamos que el verbo tiene un adjunto interno no visible, pero que se puede recuperar por el texto global 
de la noticia ("testimonio»). El circunstancial apunta a establecer el modo como se llevó a cabo la acción.

El enunciado (8) tiene como núcleo la forma "florean» y sus adjuntos son:

Sujeto: Monos. Objeto directo: al ciego. El sujeto es un agente, esto es, realiza la acción. Se nota que el objeto directo se refiere a una persona y eso ha obligado a construirlo con la preposición "a». La preposición "a» cumple con muchas funciones en el sistema de la lengua y una de ellas es, justamente, la marca de objeto directo referido a personas.

El enunciado (9) tiene como núcleo la forma «achicharra» y sus adjuntos son:

Sujeto: Fuego. Objeto directo: hermanitas. El sujeto se refiere a un fenómeno que causa un efecto (no a un agente) y el objeto directo, aunque es humano, se ha construido sin la preposición «a».

El enunciado (10) es un grupo oracional coordinado en el que la primera oración tiene una forma verbal perteneciente a la jerga y la segunda oración, una forma verbal estándar. La primera parte de la oración se analiza simplemente en términos de un núcleo (arruga) y un sujeto adjunto (Lulú). El sujeto es paciente, esto es, padece el acto de "arrugar».

El enunciado (11) tiene como núcleo la forma «chapan» y sus adjuntos son:

Sujeto: Tácito. Objeto directo: Tula. Circunstancial: limpiando jatazo. El sujeto se recupera gramaticalmente con el morfema $n$ del núcleo verbal y por el contexto se sabe que se refiere a la policía. Dado que el objeto directo es una persona, se ha construido con la preposición. El circunstancial usa el gerundio para indicar la simultaneidad con respecto a la acción principal del enunciado.

El enunciado (14) tiene como núcleo la forma "se forró» y sus adjuntos son:

Sujeto: Ingeniero. Circunstancial: con 600 dólares. La forma verbal es pronominal porque la acción es refleja, esto es, incide en el mismo sujeto. El sujeto es un beneficiario de la acción, no es un agente. 
El enunciado (15) tiene como núcleo la forma «plomean» y sus adjuntos son:

Sujeto: Tácito. Dado que la lengua castellana se rige por el parámetro pro drop, es posible la elisión del sujeto que se recupera por información morfológica. Objeto directo: «chibolo chichero». Se nota que el objeto directo sigue la fórmula $\mathrm{N}+$ Adj. dado que el adjetivo es un atributo de «chibolo». Asimismo, notamos que se ha omitido la preposición «a» en el complemento directo.

El enunciado (16) tiene como núcleo la forma «calatean» y sus adjuntos son:

Sujeto: Piratas. Objeto directo: 50 pasajeros. Circunstancial: en bus. El sujeto expresa el agente de la acción. Nuevamente, observamos que se ha omitido la preposición en la construcción del objeto directo (dado que es humano). El circunstancial es de índole locativa.

El enunciado (17) tiene como núcleo la forma «tumba» y sus adjuntos son:

Sujeto: Gripe. Objeto directo: a Chichi Valenzuela. El sujeto es la causa que acarrea un efecto. Aquí, el objeto directo se ha construido con la preposición «a».

El enunciado (18) tiene como núcleo la forma "chapan» y sus adjuntos son:

Sujeto: Tácito. Objeto directo: Rey del bujiazo. El sujeto es invisible por cuanto gramaticalmente se puede recuperar por el morfema del verbo y se piensa en la policía como agente, lo que se corrobora con la lectura de la noticia completa. Observamos que la construcción del objeto directo no ha contemplado el uso de la preposición.

El enunciado (19) tiene como núcleo la forma «se limpia» y sus adjuntos son:

Sujeto: Chakana. Circunstancial: de firmas falsas. La forma verbal es pronominal por cuanto la acción es refleja, esto es, recae en el mismo sujeto.

El enunciado (1) tiene como núcleo la locución verbal «pasan por caja». Esta lexía se debe analizar de manera gestalt, como una unidad 
compleja. Equivale a una estructura sintáctica de verbo + objeto directo (verbigracia, cobrar honorarios). Su único adjunto es la frase nominal «naranjeros».

El enunciado (2) tiene como núcleo la locución verbal «se para bobo». Sus adjuntos son:

Sujeto: Tácito. Objeto indirecto: le. Circunstancial: en pleno chuculún. La forma verbal indica una acción refleja y, por ello, se ha reforzado con el pronombre «le». Se trata de un sujeto paciente.

El enunciado (3) tiene como núcleo la locución verbal «hace puré» y sus adjuntos son:

Sujeto: Taxi. Objeto directo: a loquito. El objeto directo se ha construido con la preposición «a».

El enunciado (10) tiene como núcleo la lexía «mueve la lengua» y sus adjuntos son:

Sujeto: Mufarech. Circunstancial ${ }_{1}$ : mañana. Circunstancial ${ }_{2}$ : para soltar descargos. El primer circunstancial es de índole temporal y el segundo expresa finalidad. En principio, la cantidad de circunstanciales no tiene límite.

El enunciado (13) tiene como núcleo la locución verbal «da vuelta». Sus adjuntos son:

Sujeto: «Teutón». Objeto directo: «veci», forma apocopada de «vecina». Notamos también que se ha omitido la preposición «a». Circunstancial: "por no aceptar pizza». El sujeto cumple un papel de agente. El circunstancial expresa el motivo de la acción descrita por la locución verbal.

\section{Análisis cognitivo}

Como han mostrado tan persuasivamente Lakoff y Johnson (1980), los procedimientos tradicionalmente conocidos como retóricos (verbigracia, las metáforas) son muy rentables en la construcción del sentido del lenguaje cotidiano. Por ello, los fenómenos traslaticios que observamos en la configuración del estilo basilectal de la prensa chicha pueden entenderse como ejemplos de construcciones cog- 
nitivas que se plasman en toda una imaginería. En consecuencia, el universo semántico plasmado en los textos de la prensa sensacionalista se puede entender mejor desde una perspectiva cognitiva.

Desde la obra temprana de Neisser (1976), los procesos como ver, oír y recordar se entienden de manera cognitiva, esto es, como actos de construcción mental que pueden hacer un uso mayor o menor de la información sensorial en virtud de las circunstancias. A partir de esta constatación teórica, se colige que la cognición, en general, es un proceso mediante el cual la información sensorial es transformada, reducida, elaborada o almacenada de múltiples maneras. Se puede decir que el uso de la información depende fuertemente de las operaciones cognitivas.

En este marco, podemos entender que las formas discursivas de la prensa chicha subtienden un conjunto de imágenes y de espacios mentales que obedecen a ciertas estrategias cognitivas. El análisis del discurso chicha entraña postular, por ello, una imaginería chicha asociada a un pensamiento en el que opera la omnímoda discriminación de la sociedad peruana. Esta imaginería se proyecta en el discurso basilectal y en ciertas propiedades de estos diarios descritas por los estudiosos del fenómeno de la comunicación (García Canclini 1995, Zubieta 2000, Sunkel 2002). En consecuencia, no es casual que en los periódicos chicha se dé el empleo de lo que, con una sinestesia, podemos llamar colores estridentes. Además, esto último se halla relacionado con una característica del consumo de este tipo de periódico: la lectura ocasional en los puntos de venta (esto es, en los quioscos). Dicho sea en passant, sobre la base de esta lectura ocasional se ha hecho la inferencia de que hay un interés político subyacente que financia estos diarios (porque, de otro modo, ¿cómo explicar el fomento de una lectura que no redunda en ningún pago por parte del ocasional consumidor?).

El análisis cognitivo de las formas discursivas de la prensa chicha se hace en virtud de dos nociones claves de la linguiística cognitiva: la imaginería y los espacios mentales. Según Jackendoff (2002: 348), la imaginería entraña un procesamiento mental de índole semántica, 
por lo que es crucial para construir e interpretar los mensajes. En términos de Langacker (1987), la imaginería permite construir varias imágenes para una misma situación objetiva. La noción de imaginería subsume, como una de sus modalidades, a la metáfora.

Sin lugar a dudas, la metáfora es el procedimiento cognitivo más empleado en las construcciones verbales de los periódicos chicha. De acuerdo con la interpretación clásica de Aristóteles (1990), la metáfora es una comparación breve que ejecuta una transferencia de significado que tiene lugar sobre la base de una relación semántica de semejanza. Esta visión ha sido objetada razonablemente por Searle (1979) y, luego, esta crítica ha dado pie a la conformación de la actual teoría cognitiva de la metáfora (Mc Cormac 1985 y Chamizo 1998). El aporte principal del enfoque cognitivo es que analiza un fenómeno como la metáfora más allá de su concreción textual y se adentra en los procesos mentales que están en juego. De esa manera, la teoría adquiere el valor epistemológico de la representatividad (Bunge 1985) y supera el enfoque fenomenológico anclado en el texto. En ese sentido, podemos recuperar la intuición clásica de Henle, para quien la metáfora se sustenta en un principio cognitivo de iconicidad (o cuasi-iconicidad): cuando se piensa metafóricamente, hay una correlación entre espacios mentales y se destaca una propiedad reflejada. Evidentemente, la correcta intelección de las metáforas entraña trascender los meros planos del lenguaje y adentrarse en los meandros de la mente y de la experiencia humana: "The essence of metaphor is understanding and experiencing one kind of thing in terms of another" (Lakoff y Johnson 1980: 5).

En virtud del modelo de Fauconnier (1995), las modalidades linguiísticas manifiestas, aunque de manera infradeterminada, constituyen claves para comprender los procesos que tienen lugar detrás de las escenas verbales. Tales escenas son el resultado de operaciones cognitivas que vinculan determinados espacios mentales, los verdaderos lugares de la configuración semántica.

En la medida en que los textos de la prensa «chicha» operan con traslaciones semánticas, se puede predecir que harán uso de una 
amplia gama de ironías, metáforas y metonimias. Uno de los postulados de la linguiística cultural (Palmer 1996) es que el inventario de la imaginería metafórica es muy rico y esencialmente abierto (esto es, constantemente se pueden construir nuevas formas metafóricas). Por esta razón, no diremos nada a priori acerca de los recursos cognitivos posibles en estos discursos. En lo que sigue, veremos, en cada caso, cómo la imaginería chicha ha procesado y configurado el sentido del verbo.

En el enunciado (1), la locución «pasar por caja» se refiere al hecho de cobrar los haberes. Esta referencia se ha construido gracias a un procedimiento metonímico. En efecto, la acción de "pasar por caja» se asocia con el hecho de cobrar dinero en efectivo, dado que el lexema 'caja' nos remite al espacio mental del pago y del cobro. Por esta razón, la metonimia se torna evidente e, incluso, se ha cristalizado en el lenguaje familiar.

En el enunciado (2), la locución "pararse el bobo» es una metáfora expresiva para referirse al hecho del paro cardiaco. La analogía metafórica entre el bobo (como también se le llama al reloj) y el corazón es evidente: el mecanismo de funcionamiento entraña una acción repetida y automática. La metáfora vincula dos espacios mentales, el reloj y el corazón, en virtud de un automatismo cuyo mecanismo reiterativo se asocia, en el saber ordinario, con lo no racional.

En el enunciado (3), la locución «hacer puré» entraña dos procesos fusionados: la metáfora y la hipérbole. El auto pasa por encima del infeliz, algo así como se opera en la papa para hacer puré. Además, se trata de una comparación un tanto excesiva, exagerada; razón por la cual, se ha trabajado con la hipérbole. Los espacios mentales configuran una imagen exagerada que conlleva un efecto de humor patente.

En el enunciado (4), la forma "pelaba» es una metáfora expresiva para aludir al acto de un robo. En efecto, robar entraña quitar algo, así como pelar es quitar algo. La analogía es evidente y es la base para la construcción metafórica. La vinculación entre los dos espacios mentales (la acción de pelar y la acción de robar) no es la única 
posible, por ello implica una operación de selección. El enlace selectivo entre los espacios mentales establece una imagen mental muy rentable en el mundo cotidiano.

En (5), el verbo "planchar» es una metáfora construida sobre la base del símil entre la acción de la plancha sobre la ropa y la acción de la cirugía sobre el rostro: en ambos casos se trata de desaparecer arrugas o pliegues. La imaginería, en este caso, hace una descripción vívida de espacios mentales ligados con una transformación estética (de la ropa como efecto de la plancha y del rostro como efecto de la cirugía).

La imaginería cognitiva de (6) se funda en varios procesos. Primero, el titular juega con la ambigüedad del verbo ya que "chancar» suele tener alusiones eróticas. Empero, sobre la base de la lectura del texto de la noticia, nos percatamos de que se trata de otro uso metafórico del verbo: estudiar. En consecuencia, hay una carga irónica evidente en el enunciado. Sin duda, el texto juega con dos posibles espacios mentales para que la lectura de la noticia conlleve un efecto de hilaridad.

En el enunciado (7), la frase "cantó con lágrimas» es una antífrasis irónica con la cual el redactor hace escarnio de la cantante Dina Páucar. Ella es una artista famosa por su canto, pero la noticia se refiere al testimonio que dio en un proceso judicial. Es decir, no se trata de un canto literal, por lo que la ironía establece, cognitivamente, el juego entre espacios mentales en contraste.

En el enunciado (8), el verbo «florean» es una metáfora con la cual se construye un sentido laudatorio: la imagen de lanzar piropos a alguien. El símil de base es evidente e, incluso, su sentido traslaticio ya está fijado en el uso. Se trata de una imagen construida sobre la base de un vínculo entre espacios mentales transmitida intergeneracionalmente.

El enunciado (9) construye su noticia sobre la imagen de una hipérbole. En efecto, las niñitas que sufrieron las quemaduras probablemente no fueron literalmente «achicharradas», pero la hipérbole tiene la virtud de incrementar el contenido semántico con fines ex- 
presivos. El lazo entre espacios mentales busca el efecto de crear una imagen de gran impacto cognitivo.

El enunciado (10) se ha construido con el tropo de la sinécdoque. En efecto, «mover la lengua» es un recurso expresivo para referirse a «hablar». El esquema lógico es pars pro toto, en la medida en que el movimiento de la lengua es una actividad física integrante de la emisión del acto de habla. La sinécdoque nos remite a un modo de la imaginería que podemos llamar experiencialista, esto es, los sentidos abstractos se asocian con significaciones ligadas a lo concreto. Por ello, la sinécdoque es una clave cognitiva para captar el enlace entre dos espacios mentales, uno abstracto y otro concreto.

En el enunciado (11) se da una metáfora por la cual el verbo «arrugar» alude a una suerte de intimidación. La riqueza polisémica del verbo «arrugar» obliga a precisar la acepción específica en cada caso. Aquí despliega el sentido de retroceder por temor. Nótese que esta interpretación quizás no se ajuste a la realidad (probablemente, la lideresa no apoya la interpelación por otras razones), pero es el matiz que quiso darle el redactor de la noticia y, en forma velada, se entiende como una crítica. En tal sentido, vemos que la noticia construye una imagen mental no exenta de finalidad política.

El enunciado (12) emplea la forma "chapar» en el sentido de «atrapar» y conviene estar atentos frente a la abigarrada polisemia de este verbo. La forma «limpiar», construida en gerundio, es una metáfora irónica que alude a un robo. Se trata de un efecto retórico múltiple porque, incluso, puede notarse también un efecto hiperbólico. La metáfora se construye sobre la analogía entre limpiar como sustraer la suciedad y el acto de robar (la sustracción de bienes). La antífrasis radica en que limpiar tiene una valencia positiva, mientras que el robo está condenado en toda sociedad. La hipérbole consiste en que «limpiar» como metáfora de robo alude a una sustracción total, lo que no puede ser cierto; ergo, es una exageración. Al poner el nombre «Tula», el titular hace uso de una falacia retórica que consiste en captar la atención mediante una referencia equívoca (obviamente, no se trata de la célebre artista Tula Rodríguez). Se entiende que el 
uso del nombre entraña el juego entre dos espacios mentales en el modo de la activación de una parte de la memoria (en un primer momento, el lector pensará en la artista como referente de la noticia).

El enunciado (13) exhibe la lexía "dar vuelta» que es una sinécdoque de «matar». Se trata de una construcción expresiva muy utilizada en la lengua coloquial y que, por ello, es rentable en la conformación de noticias. Un modo de matar a alguien es mediante una torsión del cuello que produce un instantáneo y fulminante paro respiratorio. Así, esta modalidad se ha generalizado (mediante sinécdoque) para referirse al asesinato sin más. El enunciado nos sugiere la construcción de una imagen sobre la base de la relación entre dos espacios mentales. En este caso, la relación se puede entender como una generalización.

En el enunciado (14), el verbo «forrarse» es una metáfora expresiva para referirse a un enriquecimiento. Por ello, vemos que en la noticia hay una hipérbole muy clara porque 600 dólares no significa enriquecimiento. Este caso nos da pie para conjeturar que la interpretación de las imágenes depende del contexto social, por cuanto en una sociedad opulenta no sería posible entender que alguien exprese esa hipérbole (más bien, se pensaría en una antífrasis).

En el enunciado (15), la forma verbal «plomean» se refiere al acto de disparar contra alguien. Dado que las balas son de plomo, la forma verbal es una clara sinécdoque que sigue la fórmula pars pro toto. Al disparar contra alguien balas y resultar éste baleado, por extensión se puede decir que ha sido "plomeado». En consecuencia, "plomear» sería una sinécdoque de «balear» y como tal constituye una imagen mental efectiva y paladina de la situación.

En el enunciado (16), la forma «calatear» es una metáfora expresiva para referirse al acto de robar. La construcción de la noticia no es muy clara respecto de si, en efecto, se les quitó también toda la ropa; razón por la cual podríamos pensar en un efecto hiperbólico presente en la redacción. En este caso, la imagen mental genera un efecto de humor. 
En el enunciado (17), el verbo "tumbar» es una metonimia hiperbólica para referirse al hecho de quedar postrado en cama por causa de una enfermedad. La metonimia presenta la vinculación de un espacio mental (el efecto de caer en cama) con otro espacio mental (la causa, esto es, la enfermedad) y hay una clara hipérbole por cuanto «tumbar» alude a un efecto letal que no está presente en la noticia. La hipérbole produce una imagen que busca una visualización cognitiva que tiene múltiples efectos (inteligibilidad, atención, humor, etc.).

La imaginería que proyecta el enunciado (19) implica la operación de dos procesos cognitivos. La forma «limpiarse» alude a librarse de cargos y, en tal sentido, es una metáfora expresiva. El sujeto «Chakana» es una metonimia por la cual el símbolo se pone en lugar de la institución (el partido político Perú posible). La polisemia del verbo sirve para contrastar el análisis de este enunciado con el llevado a cabo en el enunciado (12), de tal manera que la polisemia se puede entender como el efecto de espacios mentales correspondientes a una misma categoría cognitiva básica.

En el enunciado (20), la forma "decir de todo» es claramente una hipérbole y tiene un sentido negativo en este contexto (aunque se puede pensar en espacios mentales donde no se da necesariamente este efecto negativo). La exclamación retórica «iVaya "piropos»!» es una antífrasis evidente que se puede inferir con facilidad, dado que como ha mostrado Giora (1995) en la ironía hay una negación implícita. Este último comentario nos lleva a señalar que el uso de las comillas es redundante, pero bien se puede pensar en un pleonasmo gráfico con el cual el redactor quiso asegurar la lectura irónica. Como ha mostrado Lyons (1995), en la lengua oral hay un contorno prosódico que produce una modulación no exenta de efectos semánticos. En particular, la estructura prosódica sirve para interpretar el sentido irónico de un enunciado y en la escritura ello se puede representar pálidamente con las comillas.

En el enunciado (21) observamos varios efectos de la imaginería chicha. La forma verbal «matan» entraña un uso directo del sentido 
léxico, pero la palabra «soplón» entraña una construcción metafórica propia de la vida cotidiana: la delación. Los puntos suspensivos construyen un juego de sentido que tiene una evidente carga humorística, acorde con la visión sensacionalista de la prensa chicha y que se traduce, muchas veces, en negligencia.

El enunciado (22) juega con una cita directa (evidentemente construida por el redactor) que utiliza una frase holofrástica. En efecto, "dar con machete» configura globalmente una efectiva imagen metafórica de una crítica dura, acerba, lapidaria. Desde el nombre asignado al ex presidente Toledo ("Choledo») se utiliza un estereotipo con efectos hilarantes.

\section{Conclusión}

Los análisis que hemos llevado a cabo nos han permitido corroborar las intuiciones que teníamos acerca de la construcción gramatical y cognitiva en los discursos de la prensa chicha. El análisis funcional (en el sentido de la glosemática) permite establecer que la sintaxis de una oración se organiza mediante la incidencia en torno a un núcleo y la incidencia se entiende como el desarrollo de adjuntos. Aunque se ha afirmado que hay adjuntos opcionales, se puede decir que estos adjuntos no se visibilizan en la estructura porque se pueden recuperar mediante el contexto y el cotexto. Hemos observado que hay una versatilidad en el uso de la preposición como marca de objeto directo humano, lo que quizá podría atribuirse a que el orden básico del castellano es sujeto - verbo - objeto y ese orden evita caer en alguna interpretación ambigua. El análisis gramatical sugiere, entonces, un recurso apoyado en la noción hjelmsleviana de catálisis. Este procedimiento implica la recuperación de elementos no visibles en la proferencia, pero que son necesarios para dar cuenta de la estructura gramatical de las oraciones. La catálisis es un mecanismo que funciona con la ayuda de la propia estructura gramatical, dado que permite predecir la presencia de elementos no visibles en la proferencia real. 
Con respecto al análisis cognitivo, hemos visto que la configuración del sentido en la prensa chicha se construye sobre la base de mecanismos como la metonimia, la metáfora, la hipérbole, la ironía, la sinécdoque y hasta el pleonasmo. Es más, la riqueza del sentido demanda a veces que haya una configuración múltiple de tales procesos cognitivos y, dado que estos mensajes tienen un efecto conativo patente, hasta se hace uso de ciertas falacias retóricas para conformar la especial imaginería de la cultura chicha proyectada en estos periódicos.

La dinámica de la vinculación de los espacios mentales en la imaginería chicha busca optimizar la comprensión de los mensajes verbales, dado que los enlaces entre espacios mentales utilizan ciertos pensamientos que se anidan en la cultura popular y forman parte de la memoria de los hablantes. En virtud de que la imaginería chicha necesita el cumplimiento óptimo de la transferencia de la intención comunicativa, hemos notado que se verbaliza en recursos ya fijados en la cultura popular. En efecto, el empleo de formas innovadoras (verbigracia, una metáfora creativa) podría constituirse en un óbice para la comprensión, lo que sería letal para el consumo de las publicaciones sensacionalistas.

Creemos que este tipo de análisis aplicado a un corpus más extenso podría echar luces sobre la manera como la cultura determina el lenguaje cotidiano y como el lenguaje cotidiano transforma la propia cultura: la imaginería chicha se nutre de (pero, a la vez, refuerza) la visión estereotipada de un amplio sector de los peruanos y, por ello, es un mecanismo efectivo de perpetuar la omnipresente discriminación de nuestra sociedad.

\section{Referencias bibliográficas}

Alarcos Llorach, Emilio (1994): Gramática de la lengua española. Madrid, Espasa.

Albaladejo, Tomás (1991): Retórica. Madrid, Síntesis.

Alcocer Martínez, Augusto (2001): «El sociolecto de los escolares limeños». Lexis, XXV, 1 y 2; pp. 15-31. 
Bickerton, Derek (1975): Dynamics of a Creole System. Cambridge, Cambridge University Press.

Bunge, Mario (1985): Teoría y realidad. Ariel, Barcelona.

Cappelini, Mónica (2004): «La prensa "chicha” en el Perú». Revista Latinoamericana de Comunicación Chasqui, diciembre; pp. 32-37.

Chamizo, Pedro (1998): Metáfora y Conocimiento. Málaga, Analecta Malacitana.

Fauconnier, Gilles (1998): «Mental spaces, language modalities and conceptual integration». En M. Tomasello (ed.) The New Psychology of Language: Cognitive and Functional Approaches to Language Structure. New Jersey, Lawrence Erlbaum.

García Canclini, Néstor (1995): Consumidores y ciudadanos. México, Grijalbo.

Giora, Rachel (1995): «On Irony and Negation». Discourse Process, 19; 2; pp. 239-264.

Henle, Paul (1958): "Metaphor”. En Paul Henle (ed.) Language, Thought, and Culture. Ann Arbor, University of Michigan Press.

Hjelmslev, Louis (1970): Prolegómenos a una teoría del lenguaje. Madrid, Gredos.

Jackendoff, Ray (2002): Foundations of Language. Oxford, Oxford University Press.

Kosslyn, Stephen (1994): Image and Brain. MIT Press, Cambridge Ma. Lakoff, George y Johnson, Mark (1980): Metaphors We Live By. Chicago, University of Chicago Press.

Lang, George (2000): Entwisted Tongues: Comparative Creole Literatures. Ámsterdam, Atlanta.

Langacker, Ronald (1987): Foundations of Cognitive Grammar. Vol. I. Theoretical Prerequisites. Stanford, Stanford University Press, (California).

Lázaro Carreter, Fernando (1968): Diccionario de términos filológicos. Madrid, Gredos.

Lyons, John (1995): Semántica lingüística. Barcelona, Paidós. Martinet, André (1978): Estudios de sintaxis funcional. Madrid, Gredos. 
Mc Cormac, Eric (1985): A Cognitive Theory of Metaphor. Oxford, Oxford University Press.

Neisser, Ulric (1976): Cognition and Reality. San Francisco, Freeman.

Palmer, Gary (1996): Lingüística cultural. Madrid, Alianza Editorial.

Real Academia Española (2001): Diccionario de la lengua española. Madrid, Espasa.

Searle, John (1979): Expression and Meaning. Cambridge, Cambridge University Press.

Sunkel, Guillermo (2002): La prensa sensacionalista y los sectores populares. Bogotá, Norma.

Tesnière, Lucien (1959): Éléments de Syntaxe Structurale. París, Éditions Klincksieck.

Zubieta, Ana María (2000): Cultura popular y cultura de masa. Buenos Aires, Paidós. 